\title{
Structure of the 2-isopropylaminoethanol isolated molecule: Conformational analysis and intramolecular interactions
}

\author{
Sandra C.C. Nunes ${ }^{\mathrm{a}, *}$, M. Ermelinda S. Eusébio ${ }^{\mathrm{a}}$, A.J. Lopes Jesus ${ }^{\mathrm{b}}$, Mário T.S. Rosado ${ }^{\text {a }}$, J.S. Redinha ${ }^{\mathrm{a}}$

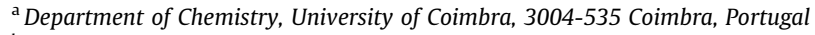 \\ ${ }^{\mathrm{b}}$ Faculty of Pharmacy, University of Coimbra, 3004-295 Coimbra, Portugal
}

\section{A R T I C L E I N F O}

\section{Article history:}

Received 19 March 2008

Received in revised form 5 May 2008

Accepted 21 May 2008

Available online $\mathrm{xxxx}$

\section{Keywords:}

2-Isopropylaminoethanol

Conformational analysis

Intramolecular hydrogen bonding

NBO analysis

DFT calculations

\begin{abstract}
A B S T R A C T
In this paper, a systematic exploration of all the possible conformers of 2-isopropylaminoethanol (2-IPAE) was carried out using the Density Functional Theory (B3LYP) and the $6-311++G(d, p)$ basis set. At this level, 66 unique conformers within a Gibbs energy range of $c a .31 \mathrm{~kJ} \mathrm{~mol}^{-1}$ were found in the potential energy surface and their geometrical and thermodynamic properties were determined and discussed. A significant molecular strain was evidenced by the dihedrals and distances between non-bonded hydrogen atoms. According to the geometrical parameters, a $\mathrm{O}-\mathrm{H} \cdots \mathrm{N}$ hydrogen bond was found to be present in the three most stable conformers, representing $68 \%$ of the conformational composition at $298.15 \mathrm{~K}$. The energetic and geometrical data derived from the DFT calculations were further complemented by a NBO analysis of the most stable conformers.
\end{abstract}

(c) 2008 Elsevier B.V. All rights reserved.

\section{Introduction}

The aim of this paper is the study of the structure of 2-isopropylaminoethanol (2-IPAE) in the gas phase. This molecule represents a molecular fragment common to various compounds used as $\beta$-blockers in the treatment of cardiovascular diseases [1,2]. For this reason, the knowledge of the structure of this compound is important as it provides a valuable contribution to the interpretation of the drug structure and, therefore, a tool to better understand its biological activity. Indeed, the behavior of a drug as agonist or antagonist depends on the fitting of its structure to that of the receptors [3]. The distance between the polar groups, which are the preferential sites for the interaction with the receptor, are markedly dependent on the conformation adopted by the drug molecule. Moreover, the exploration of the conformational landscape and the characterization of the most stable arrangements of 2-IPAE enables the selection of the low-energy structures to be used as input in the study of more complex systems [4,5]. In fact, the relatively moderate size of this molecule allows a deep investigation of some conformational features at a higher level of theory, which is rather difficult to undertake in the $\beta$-blocker molecules [6,7]. In addition, this compound has various technological applications, such as in corrosion control and metal working [8].

The knowledge of the structure of the isolated molecule is the first step to study any compound, whatever the state of matter un-

\footnotetext{
* Corresponding author.

E-mail address: snunes@qui.uc.pt (S.C.C. Nunes).
}

der consideration. In fact, the effect of intermolecular interactions can only be evaluated from the comparison of the molecular properties in the state under investigation with those referred to the isolated molecule [9-11]. The gaseous state as an ensemble of non-interacting molecules is also commonly used as a reference state for the thermodynamic properties.

In the present paper, an exhaustive conformational search of the 2-IPAE molecule using Density Functional Theory (DFT) was performed. From these calculations, some of the geometrical parameters and the thermodynamic properties of all conformers were determined and used to investigate the most important conformational features accounting for their stabilization. Particular attention was given to the intramolecular interactions. From the individual data obtained for individual conformers, the thermodynamic properties of the 2-IPAE molecule were determined. The results were further complemented with the data supplied by the Natural Bond Orbital (NBO) analysis.

\section{Computational methods}

The conformational structure of the 2-IPAE molecule can be defined by four relevant dihedrals: $\varphi_{1}\left(\mathrm{H}_{8} \mathrm{O}_{1} \mathrm{C}_{2} \mathrm{C}_{3}\right), \varphi_{2}\left(\mathrm{O}_{1} \mathrm{C}_{2} \mathrm{C}_{3} \mathrm{~N}_{4}\right), \varphi_{3}$ $\left(\mathrm{C}_{2} \mathrm{C}_{3} \mathrm{~N}_{4} \mathrm{C}_{5}\right)$ and $\varphi_{4}\left(\mathrm{C}_{3} \mathrm{~N}_{4} \mathrm{C}_{5} \mathrm{H}_{14}\right)$. The atom numbering scheme is given in Fig. 1. Assuming three orientations for each of the dihedrals, i.e., gauche $+\left(g+, \approx 60^{\circ}\right)$, gauche $-\left(g_{-}, \approx-60^{\circ}\right)$ and anti $\left(a, \approx 180^{\circ}\right)$, the number of possible conformations for this molecule is 81 , if only one chiral center configuration at the nitrogen atom is considered. All conformations were fully optimized using the B3LYP hy- 


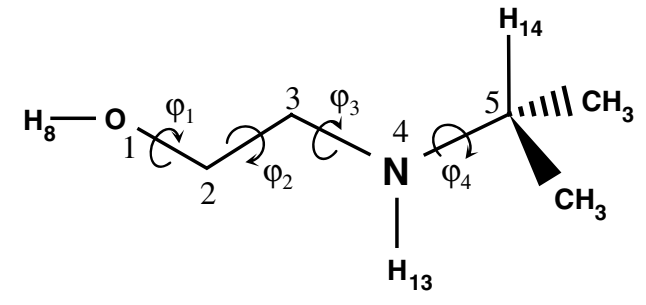

Fig. 1. Molecular structure of 2-IPAE showing the dihedral angles and atom numbering scheme.

brid functional [12-14] and the $6-311++G(d, p)$ basis set. The combination of the B3LYP hybrid functional with well-established basis set, as that used in these calculations, has been proven to be very efficient in the determination of energetic, molecular and vibrational properties of molecules similar to that of 2-IPAE [15], as well as for simple molecular systems stabilized by hydrogen bonds [16]. On the other hand, the relatively low computational cost of the DFT methods, when compared to other electron correlation methods (e.g. MP2), make it suitable to systematically explore the conformational space of high flexible molecules, as it is the case of 2-IPAE.

Additionally, the vibrational frequencies of each optimized structure were calculated at the same level. The absence of imaginary frequencies confirmed that all equilibrium structures correspond to true minima and not to any other type of stationary point on the potential energy surface. The calculations were performed using the Gaussian 03 program package [17].

NBO analysis was carried out for some selected conformers using the NBO 5.0 program [18] linked to the GAMESS software package version 22-Feb-2006 (R5) [19]. All NBO calculations were also performed at the same level of theory as that used in the geometry optimizations.

\section{Results and discussion}

\subsection{Geometrical and thermodynamic properties}

To obtain the total energy of each conformer at $298.15 \mathrm{~K}(E)$, the calculated electronic energy $\left(E_{\text {elec }}\right)$ was corrected with the zero point vibrational energy $\left(E_{\mathrm{ZPE}}\right)$, as well as with the translational, rotational and vibrational thermal energies $\left(E_{\mathrm{trans}}+E_{\mathrm{rot}}+E_{\mathrm{vib}}\right)$. The Gaussian thermochemistry output also gives the absolute entropy values calculated from the partition functions of an ideal rigid rotor and harmonic oscillator system. From the data calculated for the total energy and entropy, the enthalpy and the Gibbs energy were determined by standard thermodynamics. The relative population of the conformers was taken as a Boltzmann distribution of the Gibbs energy.

The geometry optimization of the 81 possible conformations resulted in 66 unique conformers. The values of the electronic energy, enthalpy, entropy and Gibbs energy, as well as the Boltzmann populations for all conformers are given in Table 1. The conformers are ordered according to the Gibbs energy values. The following discussion will be focused in the 12 most stable conformers, since all of the remaining ones have individual relative populations less than $1 \%$, accounting only for $6 \%$ of the overall population at $298.15 \mathrm{~K}$.

The thermodynamic properties of 2-IPAE at $298.15 \mathrm{~K}$, taken as the weighted mean of the individual data of the conformers, are $E_{\text {elec }}=-328.239512 ; H=-328.238568$ and $G=-328.282340$, all expressed in atomic units.

Although the four dihedrals can be $g+, g-$ or $a$, some of these manifest preference for certain orientations. For the 12 most abundant conformers, five of them assume a $g$ - orientation around $\varphi_{1}$, while the remaining ones are equally distributed by the two other orientations. The $\varphi_{2}$ dihedral always assumes $g+$ or $g$ - orientations and the anti orientation around this dihedral is found only for conformers with a relative population lower than $1 \%$. Regarding $\varphi_{3}$ and $\varphi_{4}$, the former is preferentially anti, while the latter is practically always $g \pm$. The influence of $\varphi_{4}$ is clearly evidenced by comparing the energy of $\mathrm{c} 11$ with that of $\mathrm{c} 1$ and $\mathrm{c} 2$. These three conformers adopt similar orientations around $\varphi_{1}, \varphi_{2}$ and $\varphi_{3}$, differing from one another in the orientation of $\varphi_{4}$, which is anti in c11, gauche+ in $\mathrm{c} 2$ and gauche - in c1. While gauche+ or gauche- has a small effect on the energy $\left(\Delta E_{\text {elec }} c a .0 .3 \mathrm{~kJ} \mathrm{~mol}^{-1}\right)$, the anti orientation increases the electronic energy by $c a .6 \mathrm{~kJ} \mathrm{~mol}^{-1}$. In Fig. 2 are depicted the four most stable conformers of 2-IPAE, all together representing $75 \%$ of the conformational composition at $298.15 \mathrm{~K}$.

One point which should be noted due to its structural significance is the diversity of values observed for the dihedrals in the various conformers. In fact, one can see that the dihedrals exhibiting a gauche+ orientation range from $40^{\circ}$ to $81^{\circ}$, those with a gauche - orientation from $-41^{\circ}$ to $-105^{\circ}$ and those of anti from $170^{\circ}$ to $-156^{\circ}$. This is a manifestation of a pronounced torsional strain in the 2-IPAE molecule. As a result of the high variability of the values of the dihedrals for each of the three standard orientations, it was not possible to identify a strainless structure to evaluate the torsional strain.

Another possible contribution to strain in the 2-IPAE molecule comes from the distortion of bond angles relative to that corresponding to $\mathrm{sp}^{3}$ hybridization. Except for $\mathrm{C}_{3} \mathrm{~N}_{4} \mathrm{C}_{5}$, whose deviation from this orientation is $6^{\circ}$, all the distortion of bond angles are lower than $2^{\circ}$. Therefore, a lesser destabilization energy due to this type of strain is expected [20].

A third factor accounting for the molecular strain comes from the distance between non-bonded hydrogen atoms shorter than the sum of their van der Waals radii. Recently, a value of $1.34 \AA$ obtained from electron density topology has been proposed for the hydrogen atom radius [21]. Thus, distances between these atoms less than $2.7 \AA$ ( $\mathrm{H} \cdots \mathrm{H}$ contacts) might be an indication that the molecule is under steric strain. These contacts result from the orientation of the molecular groups or from unavoidable crowding of vicinal hydrogen atoms. All the twelve most stable conformers exhibit two to five $\mathrm{H} \cdots \mathrm{H}$ contacts with distances ranging from 2.17 to $2.50 \AA$, indicating that there is an important steric strain in the 2IPAE molecule. The hydrogen atom of the isopropyl group yields a significant contribution to these repulsive $\mathrm{H} \cdots \mathrm{H}$ contacts.

The presence of $\mathrm{OH}$ and $\mathrm{NH}$ groups in the 2-IPAE molecule makes the existence of intramolecular bonds possible provided the structure favors this type of interaction. The feasible hydrogen bonds would be $\mathrm{O}-\mathrm{H} \cdots \mathrm{N}$ and $\mathrm{N}-\mathrm{H} \cdots \mathrm{O}$. On the geometrical point of view a classical hydrogen bond, $\mathrm{A}-\mathrm{H} \cdots \mathrm{B}$, is commonly characterized by the following structural occurrences: (i) $\mathrm{H} \cdots \mathrm{B}$ distance shorter than the sum of the van der Waals radii of both atoms ( say $<3 \AA$ ), (ii) increase of the A-H bond length and (iii) A-H $\cdots B$ angle $>110^{\circ}[22]$.

Table 2 reports the values for the parameters related to the eventual formation of one of the hydrogen bond specified above. The main conclusion to be drawn from the structural parameters regarding the above specified criteria is the existence of an $\mathrm{O}-\mathrm{H} \cdots \mathrm{N}$ intramolecular H-bond in c1, c2, c3, c8 and c11 conformers. No evidence was found for the existence of an $\mathrm{N}-\mathrm{H} \cdots \mathrm{O}$ bond.

The strength of the hydrogen bond is a valuable complementary property to characterize this interaction. The energy involved in this interaction was estimated from the following isodesmic reaction:

$$
\begin{aligned}
& \mathrm{CH}_{3} \mathrm{CH}_{2} \mathrm{NHCH}\left(\mathrm{CH}_{3}\right)_{2}+\mathrm{HOCH}_{2} \mathrm{CH}_{3} \\
& \quad \rightarrow \mathrm{CH}_{2}(\mathrm{OH}) \mathrm{CH}_{2} \mathrm{NHCH}\left(\mathrm{CH}_{3}\right)_{2}+\mathrm{CH}_{3} \mathrm{CH}_{3}
\end{aligned}
$$


Table 1

Dihedral angles, relative electronic energy, enthalpy, entropy, Gibbs energy and Boltzmann population for the 2-IPAE conformers ${ }^{\mathrm{a}}$

\begin{tabular}{|c|c|c|c|c|c|c|c|c|c|}
\hline \multirow[t]{2}{*}{ Conformer } & \multicolumn{4}{|c|}{ Dihedrals $^{\mathrm{b}}$} & \multirow[t]{2}{*}{$\Delta E_{\text {elec }}\left(\mathrm{kJ} \mathrm{mol}^{-1}\right)$} & \multirow[t]{2}{*}{$\Delta H\left(\mathrm{~kJ} \mathrm{~mol}^{-1}\right)$} & \multirow[t]{2}{*}{$\Delta S\left(\mathrm{~J} \mathrm{~mol}^{-1} \mathrm{~K}^{-1}\right)$} & \multirow[t]{2}{*}{$\Delta G\left(\mathrm{~kJ} \mathrm{~mol}{ }^{-1}\right)$} & \multirow[t]{2}{*}{ Pop. $(298 \mathrm{~K}) /$} \\
\hline & $\varphi_{1}$ & $\varphi_{2}$ & $\varphi_{3}$ & $\varphi_{4}$ & & & & & \\
\hline $\mathrm{c} 1$ & -41 & 58 & -168 & -43 & 0.00 & 0.00 & 0.00 & 0.00 & 30.04 \\
\hline c2 & -41 & 56 & -162 & 57 & -0.29 & -0.44 & -0.62 & 0.18 & 27.95 \\
\hline c3 & 40 & -54 & -87 & 48 & 2.48 & 2.50 & -0.23 & 2.73 & 10.00 \\
\hline c4 & 170 & -63 & 173 & -47 & 4.91 & 4.32 & 0.70 & 3.62 & 6.97 \\
\hline c5 & 171 & -65 & -178 & 55 & 7.43 & 6.53 & 1.33 & 5.20 & 3.69 \\
\hline c6 & -70 & -62 & 168 & -49 & 6.14 & 5.46 & 0.13 & 5.33 & 3.50 \\
\hline c7 & 81 & -57 & -169 & -43 & 7.79 & 7.62 & 1.80 & 5.82 & 2.87 \\
\hline c8 & 45 & -52 & -105 & -50 & 4.38 & 4.87 & -1.49 & 6.36 & 2.31 \\
\hline c9 & 73 & -57 & -156 & 57 & 8.35 & 8.08 & 1.41 & 6.67 & 2.04 \\
\hline c10 & -70 & -64 & 178 & 53 & 8.86 & 7.83 & 0.97 & 6.86 & 1.89 \\
\hline c11 & -41 & 57 & -165 & -174 & 6.05 & 6.40 & -0.84 & 7.24 & 1.62 \\
\hline c12 & -176 & 60 & 68 & -48 & 11.44 & 10.75 & 2.56 & 8.18 & 1.11 \\
\hline c13 & -175 & -177 & -176 & -44 & 12.53 & 11.80 & 2.96 & 8.83 & 0.85 \\
\hline c14 & -67 & -177 & -180 & -45 & 12.56 & 12.03 & 2.37 & 9.66 & 0.61 \\
\hline c15 & 63 & 180 & -179 & -45 & 12.63 & 11.97 & 2.08 & 9.89 & 0.56 \\
\hline c16 & -176 & -177 & -166 & 57 & 13.06 & 12.24 & 1.73 & 10.50 & 0.43 \\
\hline c17 & 69 & 59 & 75 & -43 & 12.39 & 11.80 & 0.87 & 10.92 & 0.37 \\
\hline c18 & 63 & 180 & -167 & 57 & 13.39 & 12.57 & 1.33 & 11.25 & 0.32 \\
\hline c19 & -67 & -177 & -167 & 57 & 13.20 & 12.61 & 1.34 & 11.27 & 0.32 \\
\hline c20 & 170 & -65 & 179 & -176 & 13.06 & 12.81 & 0.74 & 12.06 & 0.23 \\
\hline c21 & 178 & 177 & -91 & 47 & 15.99 & 15.07 & 2.36 & 12.70 & 0.18 \\
\hline c22 & -72 & 60 & 58 & -53 & 14.95 & 14.16 & 1.26 & 12.89 & 0.17 \\
\hline c23 & 72 & -56 & -155 & -172 & 14.37 & 14.81 & 1.66 & 13.15 & 0.15 \\
\hline c24 & 44 & -51 & -105 & 179 & 11.62 & 12.05 & -1.26 & 13.30 & 0.14 \\
\hline c25 & -70 & -63 & 174 & -178 & 14.35 & 13.96 & 0.59 & 13.37 & 0.14 \\
\hline c26 & -173 & 73 & -86 & 49 & 15.98 & 15.04 & 1.44 & 13.59 & 0.12 \\
\hline c27 & 179 & 180 & -112 & -50 & 15.98 & 15.20 & 1.49 & 13.71 & 0.12 \\
\hline c28 & 67 & 176 & -88 & 47 & 16.48 & 15.78 & 2.07 & 13.71 & 0.12 \\
\hline c29 & 176 & 176 & 63 & -54 & 18.15 & 17.09 & 3.36 & 13.73 & 0.12 \\
\hline c30 & -65 & 180 & -90 & 46 & 16.69 & 15.84 & 1.83 & 14.02 & 0.11 \\
\hline c31 & -61 & -180 & 66 & -52 & 17.76 & 17.15 & 2.58 & 14.57 & 0.08 \\
\hline c32 & -176 & 72 & 178 & -45 & 19.31 & 17.77 & 3.12 & 14.66 & 0.08 \\
\hline c33 & -169 & 74 & -165 & 57 & 20.39 & 18.54 & 3.83 & 14.71 & 0.08 \\
\hline c34 & 64 & 175 & 65 & -52 & 18.66 & 17.94 & 2.95 & 14.99 & 0.07 \\
\hline c35 & -67 & -178 & -111 & -50 & 16.83 & 16.17 & 1.05 & 15.12 & 0.07 \\
\hline c36 & 67 & 178 & -110 & -50 & 16.86 & 16.23 & 1.06 & 15.16 & 0.07 \\
\hline c37 & 69 & 74 & -78 & 52 & 18.08 & 16.93 & 1.44 & 15.49 & 0.06 \\
\hline c38 & -179 & -73 & 67 & -54 & 18.21 & 17.24 & 1.66 & 15.58 & 0.06 \\
\hline c39 & 66 & 57 & 99 & 57 & 18.10 & 16.94 & 0.53 & 16.41 & 0.04 \\
\hline c40 & -176 & -177 & -167 & -173 & 19.28 & 18.81 & 2.40 & 16.42 & 0.04 \\
\hline c41 & -174 & 59 & 94 & 56 & 18.40 & 17.33 & 0.53 & 16.80 & 0.03 \\
\hline c42 & 64 & -180 & -169 & -173 & 19.61 & 19.10 & 2.29 & 16.81 & 0.03 \\
\hline c43 & -164 & 76 & -118 & -42 & 21.15 & 19.75 & 2.72 & 17.02 & 0.03 \\
\hline c44 & 162 & -75 & -95 & 48 & 21.99 & 20.28 & 3.25 & 17.03 & 0.03 \\
\hline c45 & -66 & -69 & 71 & -49 & 19.56 & 18.68 & 1.60 & 17.08 & 0.03 \\
\hline c46 & -67 & -177 & -170 & -173 & 19.46 & 19.18 & 2.03 & 17.14 & 0.03 \\
\hline c47 & 65 & -65 & 92 & -42 & 20.84 & 19.50 & 1.64 & 17.85 & 0.02 \\
\hline c48 & -67 & 59 & 66 & 30 & 20.17 & 18.86 & 0.38 & 18.48 & 0.02 \\
\hline c49 & 176 & 174 & 69 & 28 & 23.42 & 21.98 & 2.83 & 19.15 & 0.01 \\
\hline c50 & 71 & -78 & 66 & -59 & 20.56 & 19.50 & 0.18 & 19.33 & 0.01 \\
\hline c51 & -61 & 178 & 95 & 57 & 22.68 & 21.39 & 2.00 & 19.39 & 0.01 \\
\hline c52 & -177 & -73 & 71 & 22 & 23.13 & 21.40 & 1.89 & 19.51 & 0.01 \\
\hline c53 & 64 & 173 & 68 & 28 & 23.63 & 22.47 & 2.29 & 20.18 & 0.01 \\
\hline c54 & 65 & 76 & -82 & -21 & 21.99 & 20.90 & 0.49 & 20.41 & 0.01 \\
\hline c55 & -65 & -72 & 71 & 27 & 24.01 & 22.30 & 1.12 & 21.17 & 0.01 \\
\hline c56 & -168 & 74 & -167 & -173 & 26.67 & 25.46 & 3.16 & 22.30 & $<0.01$ \\
\hline c57 & -175 & 58 & 91 & -175 & 23.55 & 22.90 & 0.45 & 22.45 & $<0.01$ \\
\hline c58 & 67 & 56 & 97 & -173 & 23.04 & 22.52 & -0.38 & 22.89 & $<0.01$ \\
\hline c59 & 175 & 169 & 71 & 167 & 29.50 & 28.59 & 3.83 & 24.76 & $<0.01$ \\
\hline c60 & -61 & 176 & 94 & -173 & 27.80 & 26.91 & 1.34 & 25.57 & $<0.01$ \\
\hline c61 & 65 & 168 & 71 & 167 & 29.76 & 29.18 & 3.23 & 25.95 & $<0.01$ \\
\hline c62 & -69 & 56 & 66 & 164 & 26.58 & 26.07 & -0.95 & 27.02 & $<0.01$ \\
\hline c63 & 179 & 83 & -82 & -156 & 29.79 & 29.27 & 0.01 & 29.26 & $<0.01$ \\
\hline c64 & -176 & -80 & 70 & 161 & 29.97 & 28.93 & -0.82 & 29.75 & $<0.01$ \\
\hline c65 & 69 & 83 & -80 & -159 & 31.48 & 30.87 & 0.11 & 30.76 & $<0.01$ \\
\hline c66 & -68 & -78 & 69 & 163 & 31.69 & 30.65 & -0.35 & 30.99 & $<0.01$ \\
\hline
\end{tabular}

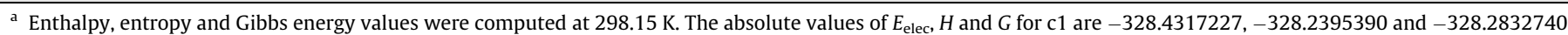
Hartrees, respectively.

b $\varphi_{1}=\mathrm{H}_{8} \mathrm{O}_{1} \mathrm{C}_{2} \mathrm{C}_{3}, \varphi_{2}=\mathrm{O}_{1} \mathrm{C}_{2} \mathrm{C}_{3} \mathrm{~N}_{4}, \varphi_{3}=\mathrm{C}_{2} \mathrm{C}_{3} \mathrm{~N}_{4} \mathrm{C}_{5}$, and $\varphi_{4}=\mathrm{C}_{3} \mathrm{~N}_{4} \mathrm{C}_{5} \mathrm{H}_{14}$.

The species involved in this reaction were obtained from the conformer under consideration by replacing the $\mathrm{OH}$ group (fragment I), the isopropylamine group (fragment II), and both groups (fragment III) by hydrogen atoms. Details of this methodology are given elsewhere [23]. The energy of each one of the species was obtained by optimizing all the internal coordinates related 


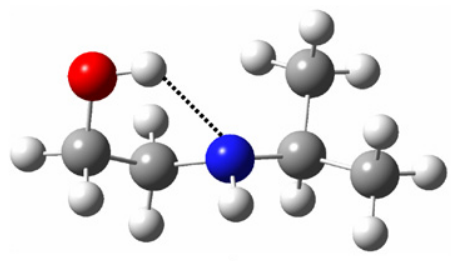

c1

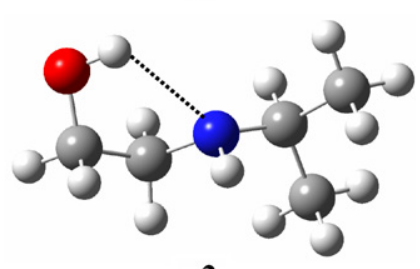

c2

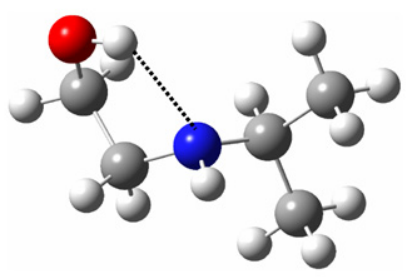

c3

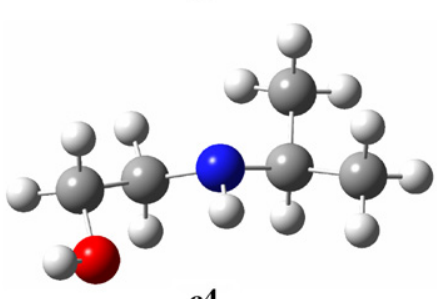

c4

Fig. 2. B3LYP/6-311++G(d,p) optimized structures of the four most stable conformers of 2-IPAE in gas phase. Dashed lines represent intramolecular hydrogen bonds.

with the substituted atom at the B3LYP/6-311++G(d,p) level of theory. The energy of the hydrogen bond is thus given by the expression: $E(\mathrm{I})+E(\mathrm{II})-E(\mathrm{III})-E$ (optimized conformer). Following this procedure, the values estimated for $\mathrm{c} 1, \mathrm{c} 2, \mathrm{c} 3, \mathrm{c} 8$ and $\mathrm{c} 11$ were $19,21,23,22$ and $21 \mathrm{~kJ} \mathrm{~mol}^{-1}$, respectively.

Aminoethanol and some of its derivatives have been object of attention by various authors [24-28]. A common finding among them is the existence of an $\mathrm{O}-\mathrm{H} \cdots \mathrm{N}$ intramolecular hydrogen bond as a stabilizing effect. Some of these works also refer to the exis- tence of a $\mathrm{N}-\mathrm{H} \cdots \mathrm{O}$ intramolecular bond $[24,27,28]$. In the case of 2-IPAE, apparently, no significant $\mathrm{N}-\mathrm{H} \cdots \mathrm{O}$ hydrogen bond is found to exist. Moreover, it should be stressed that the presence of the isopropyl group confers to 2-IPAE a quite different behavior, as the orientation around $\varphi_{4}$ plays an important role in the conformational preferences of this molecule, as has already been referred to above.

An important parameter regarding the structure-activity relationship of a drug molecule containing 2-IPAE as molecular fragment is the $\mathrm{O}_{1} \cdots \mathrm{N}_{4}$ distance as it involves two interaction centers with the receptor. The conformers of 2-IPAE with a $g+$ or $g$ - orientation about $\varphi_{2}$ (accounting to $c a$. 94\% of the equilibrium population), have $\mathrm{O}_{1} \cdots \mathrm{N}_{4}$ distances between 2.8 and $2.9 \AA$. For the conformers presenting the oxygen and nitrogen atoms more apart from one another, i.e. with an anti- $\varphi_{2}$ arrangement, this distance ranges between 3.7 and $3.8 \AA$. Those conformers are found to have a small weight in the conformational landscape of the molecule.

Regarding the characterization of the conformers by their thermodynamic properties, one can see that the first 12 conformers displayed in Table 1 are in an electronic energy range of $c a$. $12 \mathrm{~kJ} \mathrm{~mol}^{-1}$. The lowest electronic energy conformer is $\mathrm{c} 2$, which adopt gauche-, gauche+, anti and gauche+ orientation around $\varphi_{1}$, $\varphi_{2}, \varphi_{3}$ and $\varphi_{4}$ dihedrals, respectively. The structure of $c 1$ differs from that of $\mathrm{c} 2$ only in $\varphi_{4}$ that is gauche - instead of gauche+ and the energy difference between them is as small as $0.29 \mathrm{~kJ} \mathrm{~mol}^{-1}$. The following two conformers in the electronic energy ordering, c3 and c8, have identical conformations regarding the first three dihedrals $\left(g+, g_{-}, g_{-}\right)$, differing from each other in $\varphi_{4}(g+$ in the first and $g-$ in the second). It is plausible to admit that the torsional strain indicated by the values of $\varphi_{3}$ in both of these conformers is responsible for their energy increase relatively to c2 and also for the energy difference between them $\left(1.9 \mathrm{~kJ} \mathrm{~mol}^{-1}\right)$. It is worth noting that the sixth lower electronic energy conformer, c11, differs from $\mathrm{c} 1$ in $\varphi_{4}$, that is anti in the former and gauche - in the latter. From c8 to $c 10$ the electronic energy increases gradually with an increment of $c a .0 .6 \mathrm{~kJ} \mathrm{~mol}^{-1}$ and a pronounced energy increase occurs $\left(2.58 \mathrm{~kJ} \mathrm{~mol}^{-1}\right)$ from c10 to $\mathrm{c} 12$. Five of the six lower electronic energy conformers exhibit a favorable geometry for the formation of the intramolecular $\mathrm{O}-\mathrm{H} \cdots \mathrm{N}$ hydrogen bond. This fact shows the role played by this interaction in the energy stabilization of the conformers' structure.

The relative positions of many conformers changes when the enthalpy and Gibbs energy ordering are compared. For example, the lowest enthalpy conformer (c2) is the second in the Gibbs energy scale. This means that the difference of the entropic term between both conformers overcomes the enthalpy difference.

Owing to its low entropy, c8, the fifth lower enthalpy conformer, changes to the eighth in Gibbs energy ordering. For the

Table 2

Distances and angles related to hydrogen bonding for the twelve most stable conformers of 2-IPAE

\begin{tabular}{|c|c|c|c|c|c|c|c|c|}
\hline \multirow[t]{2}{*}{ Conf. } & \multicolumn{4}{|l|}{$\mathrm{O}_{1}-\mathrm{H}_{8} \cdots \mathrm{N}_{4}$} & \multicolumn{4}{|l|}{$\mathrm{N}_{4}-\mathrm{H}_{13} \cdots \mathrm{O}_{1}$} \\
\hline & $\mathrm{d}\left(\mathrm{O}_{1}-\mathrm{H}_{8}\right)^{\mathrm{a}}(\AA)$ & $\mathrm{d}\left(\mathrm{H}_{8} \cdots \mathrm{N}_{4}\right)(\AA)$ & $\alpha\left(\mathrm{O}_{1} \mathrm{H}_{8} \mathrm{~N}_{4}\right)\left(^{\circ}\right)$ & $\mathrm{d}\left(\mathrm{O}_{1} \cdots \mathrm{N}_{4}\right)(\AA)$ & $\mathrm{d}\left(\mathrm{N}_{4}-\mathrm{H}_{13}\right)^{\mathrm{b}}(\AA)$ & $\mathrm{d}\left(\mathrm{H}_{13} \cdots \mathrm{O}_{1}\right)(\AA)$ & $\alpha\left(\mathrm{N}_{4} \mathrm{H}_{13} \mathrm{O}_{1}\right)\left(^{\circ}\right)$ & $\mathrm{d}\left(\mathrm{O}_{1} \cdots \mathrm{N}_{4}\right)(\AA)$ \\
\hline c1 & 0.9680 & 2.30 & 114.1 & 2.84 & & & & \\
\hline c2 & 0.9685 & 2.27 & 115.0 & 2.82 & & & & \\
\hline c3 & 0.9692 & 2.26 & 115.4 & 2.82 & & & & \\
\hline c4 & & & & & 1.0155 & 2.41 & 105.5 & 2.86 \\
\hline c5 & & & & & 1.0163 & 2.49 & 101.4 & 2.87 \\
\hline c6 & & & & & 1.0156 & 2.47 & 107.0 & 2.93 \\
\hline \multicolumn{9}{|l|}{ c7 } \\
\hline c8 & 0.9688 & 2.28 & 114.4 & 2.82 & & & & \\
\hline \multicolumn{9}{|l|}{ c9 } \\
\hline c10 & & & & & 1.0163 & 2.45 & 103.0 & 2.94 \\
\hline c11 & 0.9684 & 2.28 & 114.4 & 2.82 & & & & \\
\hline c12 & & & & & 1.0146 & 2.57 & 100.4 & 2.92 \\
\hline
\end{tabular}

a $\mathrm{O}_{1}-\mathrm{H}_{8}$ bond length in hydrogen bond-free conformers is $0.9613 \pm 0.0002 \AA(n=24)$.

b $\mathrm{N}_{4}-\mathrm{H}_{13}$ bond length in hydrogen bond-free conformers is $1.014 \pm 0.002 \AA(n=51)$. 
same reason the seventh lower enthalpy conformer is the 11th most stable one in terms of Gibbs energy.

The values calculated for the translational entropy are $167 \mathrm{~J} \mathrm{~K}^{-1} \mathrm{~mol}^{-1}$ and those for rotational entropy lie within 117.3$118.3 \mathrm{~J} \mathrm{~K}^{-1} \mathrm{~mol}^{-1}$, respectively. The relative values of the total entropy of the conformers are given in Table 1. Fig. 3 represents the values calculated for the vibrational entropy for the 12 most stable conformers, which varies from $96 \mathrm{~J} \mathrm{~K}^{-1} \mathrm{~mol}^{-1}$ in $\mathrm{c} 8$ to $109 \mathrm{~J} \mathrm{~K}^{-1} \mathrm{~mol}^{-1}$ in $\mathrm{c} 12$. The lower entropy conformers are those exhibiting an internal hydrogen bond. This should be expected because this type of interaction decreases the frequency of the $\mathrm{O}-\mathrm{H}$ group stretch vibration.

\subsection{Natural bond orbital analysis}

The natural bond orbital (NBO) analysis provides a description of the structure of a conformer by a set of localized bond, antibonds and Rydberg extravalence orbitals. Stabilizing interactions between filled and unoccupied orbitals and destabilizing interactions between filled orbitals can also be obtained from this analysis [2931]. Therefore, NBO theory is a valuable complement to the energetic and structural data presented above.

A large number of stabilizing orbital interactions are observed in all conformers of 2-IPAE molecule, most of them between vicinal NBOs and a few between geminal or remote orbitals. The energy lowering corresponding to the interaction between a filled orbital (i) and an antibonding orbital $\left(j^{*}\right)$, is deduced from the second order perturbation of the filled orbital [29,31,32],

$E_{i, j^{*}}^{(2)}=q_{i} F\left(i, j^{*}\right)^{2} /\left(\varepsilon_{j^{*}}-\varepsilon_{i}\right)$

$q_{i}$ is the filled orbital occupancy $(\sim 2), \mathrm{F}\left(i, j^{*}\right)$ is the Fock matrix element between both NBOs and $\varepsilon_{j^{*}}$ and $\varepsilon_{i}$ are the respective energies. This energy $\left(E_{i, j^{*}}^{(2)}\right)$ is also proportional to the overlap integral $\left(S_{i, j^{*}}\right)$ of the corresponding pre-orthogonalized natural bond orbitals (PNBOs).

The sum of the values of $\left(E_{i, j^{*}}^{(2)}\right)$ exceeding a default threshold of $2 \mathrm{~kJ} \mathrm{~mol}^{-1}$ for the twelve most stable conformers is in the range of 598-653 $\mathrm{kJ} \mathrm{mol}^{-1}$. Among the most energetic donor-acceptor NBO interactions are those involving the p-type lone pair of the oxygen atom, $\mathrm{Lp}_{2} \mathrm{O}_{1}$, and the lone pair of the nitrogen atom, $\mathrm{LpN}_{4}$, with vicinal $\mathrm{C}-\mathrm{H}$ antibonds $\left(E_{i, j^{*}}^{(2)} \approx 40-30 \mathrm{~kJ} \mathrm{~mol}^{-1}\right)$.

As the filled NBOs get close together a steric repulsion occurs as a consequence of the Pauli exclusion principle giving rise to a destabilizing energy, $\left(E_{i, j}^{(s t)}\right)[33]$. The sum of the pairwise steric exchange energy for these joint NLMOs, which exceed a default threshold of $2 \mathrm{~kJ} \mathrm{~mol}^{-1}$, vary from 682 to $720 \mathrm{~kJ} \mathrm{~mol}^{-1}$. Such a high

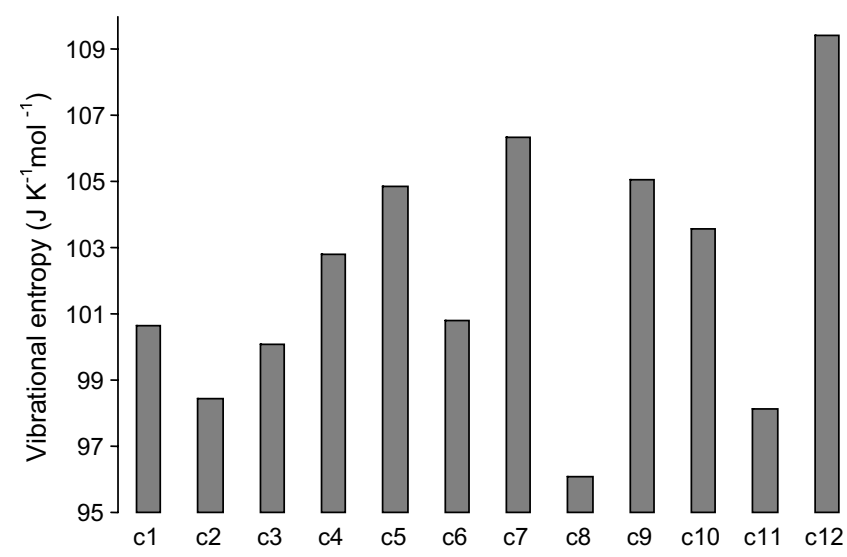

Fig. 3. Representation of the vibrational entropy at $298.15 \mathrm{~K}$ for the 12 most stable conformers of 2-IPAE. destabilizing energy estimated for the conformers is in agreement with the manifestation of molecular strain as evidenced by the geometrical data.

NBO theory can also be used to identify hydrogen bonding. The NBO approach consists of considering this interaction as an electron transfer from the donor to the acceptor [29,31]. The $\mathrm{O}_{1-}$ $\mathrm{H}_{8} \cdots \mathrm{N}_{4}$ hydrogen bond, in NBO terms, corresponds to the nitrogen lone pair $\left[\mathrm{n}\left(\mathrm{LpN}_{4}\right)\right]$ electron transfer to the antibonding $\sigma^{*}\left(\mathrm{O}_{1}-\mathrm{H}_{8}\right)$ orbital. Table 3 presents the values of $E_{i, j^{*}}^{(2)}$ and $S_{i, j^{*}}$ for the conformers exhibiting this interaction, while in Fig. 4 the corresponding PNBO overlap in conformer $\mathrm{c} 2$ is depicted. No evidence was found for the existence of an $\mathrm{n}\left(\mathrm{LP}_{2} \mathrm{O}_{1}\right) \rightarrow \sigma^{*}\left(\mathrm{~N}_{4} \mathrm{H}_{13}\right)$ hydrogen bond on the grounds of NBO interactions.

The energy values corresponding to the charge transfer in the supramolecular complex, formed by hydrogen bonding, are lower than those estimated from the geometrical parameters. Apparently, besides charge transfer, other components, such as dipoledipole interactions, contribute significantly to hydrogen bonding. In spite of the difference between the results obtained by the two methods for the hydrogen bond strength, both approaches point out small differences between the conformers.

The donor-acceptor interaction induces a repolarization of $\sigma\left(\mathrm{O}_{1}-\mathrm{H}_{8}\right) \mathrm{NBO}$, increasing the $s$ character of the natural hybrid of the $\mathrm{O}_{1}$ atom, as well as the respective polarization coefficient. However, the charge increase at $\mathrm{H}_{8}$ due to the repolarization process is attenuated by the electron occupancy of $\sigma^{*}\left(\mathrm{O}_{1}-\mathrm{H}_{8}\right)$. There-

Table 3

Second order perturbation stabilization energies $\left(\mathrm{kJ} \mathrm{mol}^{-1}\right)$ and integral overlaps corresponding to the interaction between the nitrogen lone pair and the $\mathrm{OH}$ antibond orbital for the H-bonded conformers of 2-IPAE

\begin{tabular}{lcc}
\hline Conformer & $\mathrm{n}\left(\mathrm{LpN}_{4}\right) \rightarrow \sigma^{*}\left(\mathrm{O}_{1}-\mathrm{H}_{8}\right)$ & \\
\cline { 2 - 3 } & $E_{i, j^{*}}^{(2)}$ & $\left|S_{i, j^{*}}\right|$ \\
\hline c1 & 8.41 & 0.1198 \\
c2 & 10.29 & 0.1390 \\
c3 & 10.96 & 0.1478 \\
c8 & 9.75 & 0.1347 \\
c11 & 9.83 & 0.1354 \\
\hline
\end{tabular}

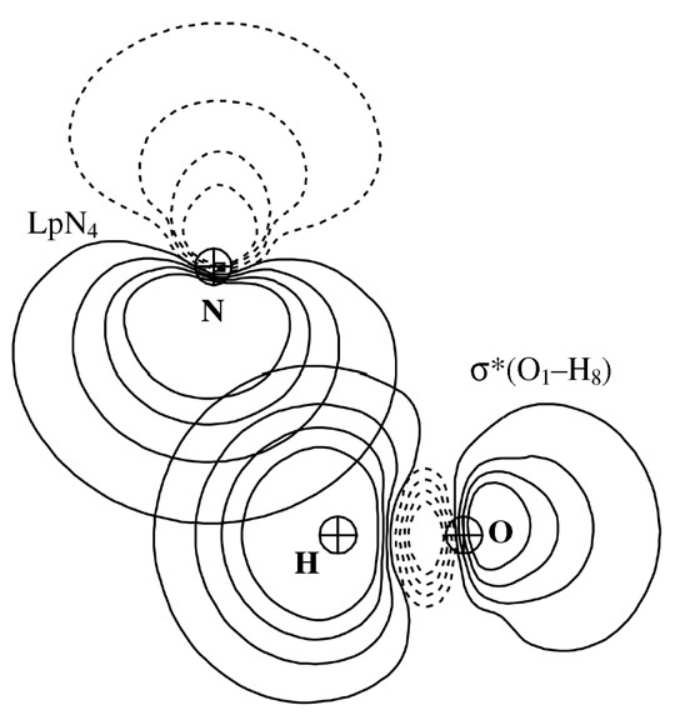

Fig. 4. Contour plot of the overlap of pre-orthogonalized natural bond orbitals (PNBOs): nitrogen lone pair $\mathrm{LpN}_{4}$ with $\mathrm{O}_{1} \mathrm{H}_{8}$ antibonding orbital, $\sigma^{*}\left(\mathrm{O}_{1}-\mathrm{H}_{8}\right)$, for the conformer c2 of 2-IPAE, calculated at the B3LYP/6-311++G(d,p) level of theory. Atomic positions are indicated by circled crosses. 
Table 4

Hybrid Composition, occupancies of the bonding and antibonding $\mathrm{O}_{1}-\mathrm{H}_{8}$ orbital and predicted charge increase on $\mathrm{H}_{8}$ atom due to intramolecular hydrogen bond formation

\begin{tabular}{|c|c|c|c|c|}
\hline Conformer & $\sigma\left(\mathrm{O}_{1}-\mathrm{H}_{8}\right)$ hybrid composition ${ }^{\mathrm{a}}$ & $\sigma\left(\mathrm{O}_{1}-\mathrm{H}_{8}\right)$ occupancy & $\sigma^{*}\left(\mathrm{O}_{1}-\mathrm{H}_{8}\right)$ occupancy & Charge increase at $\mathrm{H}_{8}$ \\
\hline c1 & $0.8610 \mathrm{sp}^{3.66}+0.5086 \mathrm{~s}$ & 1.98949 & 0.00808 & 0.014 \\
\hline$c 2$ & $0.8614 \mathrm{sp}^{3.65}+0.5079 \mathrm{~s}$ & 1.98944 & 0.00932 & 0.015 \\
\hline c3 & $0.8615 \mathrm{sp}^{3.66}+0.5077 \mathrm{~s}$ & 1.98935 & 0.01047 & 0.014 \\
\hline c8 & $0.8609 \mathrm{sp}^{3.68}+0.5088 \mathrm{~s}$ & 1.98917 & 0.00994 & 0.013 \\
\hline c11 & $0.8613 \mathrm{sp}^{3.65}+0.5081 \mathrm{~s}$ & 1.98944 & 0.00904 & 0.015 \\
\hline
\end{tabular}

${ }^{\mathrm{a}}$ Hybrid composition for the non-hydrogen-bonded conformers: $(0.8551 \pm 0.001) \mathrm{sp}^{(3.84 \pm 0.01)} \mathrm{O}_{1}+(0.5186 \pm 0.002) \mathrm{s} \mathrm{H}_{8}$.

fore, a net charge increase on the bridge hydrogen results from hydrogen bonding.

The effects of the of $\mathrm{n}\left(\mathrm{LpN}_{4}\right) \rightarrow \sigma^{*}\left(\mathrm{O}_{1}-\mathrm{H}_{8}\right)$ electron transfer for the conformers exhibiting an intramolecular hydrogen bond are displayed in Table 4. From these effects, a charge increase of $c a$. 0.014 at $\mathrm{H}_{8}$ is estimated. The natural atomic charge at this atom obtained by natural population analysis for hydrogen-bonded conformers is $0.4686 \pm 0.0009$, whereas in the non-hydrogen-bonded ones it is $0.4551 \pm 0.0033$. As was previously explained, the charge increase at the hydrogen atom of the acceptor group is also a clear manifestation of hydrogen bonding.

\section{Conclusions}

The isolated 2-IPAE molecule presents sixty six conformers within an Gibbs energy range of $31 \mathrm{~kJ} \mathrm{~mol}^{-1}$.

The 12 most stable conformers presented by this molecule, accounting for $94 \%$ of the gas phase conformational equilibrium, are characterized by a gauche \pm orientation around the $\varphi_{2}$ (OCCN) and $\varphi_{4}(\mathrm{CNCH})$ dihedrals, while the $\varphi_{3}$ dihedral assumes preferentially an anti orientation.

All the investigated conformers indicate a significant molecular strain, which is reflected in high variability of the values of the dihedral angles for each standard orientation and in the close proximity of the non-bonded hydrogen atoms. This molecular strain is also evident from the high values of the repulsion energy between filled NBOs.

Among the lower energy conformers, five exhibit an intramolecular hydrogen bond involving the nitrogen atom as the electron donor and $\mathrm{O}-\mathrm{H}$ group as acceptor. Following an isodesmic reaction, the energy involved in this interaction was predicted to be $c a$. $21 \mathrm{~kJ} \mathrm{~mol}^{-1}$. Half of this value was attributed to the hyperconjugative charge transfer from the nitrogen electron donor to the $\mathrm{O}-\mathrm{H}$ acceptor group, as was estimated from the NBO analysis. The manifestation of this interaction, in NBO terms, was reflected in the charge increase at the hydrogen atom, repolarization of the acceptor group orbital and the increment of the occupancy of the antibonding orbital acceptor group.

Although the aim of this paper is not to study the drug-receptor interaction, the data given is a valuable starting point to interpret the biological activity of drug molecules containing 2-IPAE as side chain group, as far as structural features of all conformers are presented and all types of intramolecular interactions presented by this fragment have been explored.

\section{Acknowledgment}

Sandra C. C. Nunes acknowledges Fundação para a Ciência e a Tecnologia (FCT), Lisbon, for financial support. Grant SFRH/BD/ 1902/2004.

\section{References}

[1] J.H. Atterhog, H. Duner, B. Pernow, Am. J. Med. 60 (1976) 872.

[2] Brent R. DeGeorge, W.J. Koch, J. Clin. Invest. 117 (2006) 86.

[3] T. Nagatomo, T. Ohnuki, M. Ishiguro, M. Ahmed, T. Nakamura, Jpn. J. Pharmacol. 87 (2001) 7.

[4] D.R.P. Almeida, D.M. Gasparro, L.F. Pisterzi, J.R. Juhasz, F. Fülöp, I.G. Csizmadia, J. Mol. Struct. (THEOCHEM) 666-667 (2003) 537.

[5] D.R.P. Almeida, D.M. Gasparro, L.F. Pisterzi, J.R. Juhasz, F. Fülöp, I.G. Csizmadia, J. Mol. Struct. (THEOCHEM) 666-667 (2003) 557.

[6] S.C.C. Nunes, A.J.L. Jesus, M.T.S. Rosado, M.E.S. Eusébio, J. Mol. Struct. (THEOCHEM) 806 (2007) 231.

[7] N. Sadlej-Sosnowska, J.C. Dobrowolski, A.P. Mazurek, J. Mol. Struct. 520 (2000) 165.

[8] Arkema, Some Representative Amine Applications. Available at: <www.arkema-inc.com/literature/pdf/355.pdf> (accessed March 6, 2008).

[9] A.L. Jesus, L.I.N. Tomé, M.E.S. Eusébio, J.S. Redinha, J. Phys. Chem. B 110 (2006) 9280.

[10] A.J.L. Jesus, L.I.N. Tomé, M.E. Eusébio, J.S. Redinha, J. Phys. Chem. B 109 (2005) 18055.

[11] A.J.L. Jesus, M.T.S. Rosado, M.L.P. Leitão, J.S. Redinha, J. Phys. Chem. A 107 (2003) 3891.

[12] A.D. Becke, Phys. Rev. A 38 (1988) 3098.

[13] A.D. Becke, J. Chem. Phys. 98 (1993) 5648

[14] C.T. Lee, W.T. Yang, R.G. Parr, Phys. Rev. B 37 (1988) 785.

[15] A.J.L. Jesus, M.T.S. Rosado, I. Reva, R. Fausto, M.E. Eusébio, J.S. Redinha, J. Phys. Chem. A 110 (2006) 4169.

[16] Leticia González, Otilia Mó, M. Yáñez, J. Comput. Chem. 18 (1997) 1124.

[17] M.J. Frisch, G.W. Trucks, H.B. Schlegel, G.E. Scuseria, M.A. Robb, J.R. Cheeseman, J.A. Montgomery Jr, T. Vreven, K.N. Kudin, J.C. Burant, J.M. Millam, S.S. Iyengar, J. Tomasi, V. Barone, B. Mennucci, M. Cossi, G. Scalmani, N. Rega, G.A. Petersson, H. Nakatsuji, M. Hada, M. Ehara, K. Toyota, R. Fukuda, J. Hasegawa, M. Ishida, T. Nakajima, Y. Honda, O. Kitao, H. Nakai, M. Klene, X. Li, J.E. Knox, H.P. Hratchian, J.B. Cross, V. Bakken, C. Adamo, J. Jaramillo, R. Gomperts, R.E. Stratmann, O. Yazyev, A.J. Austin, R. Cammi, C. Pomelli, J.W. Ochterski, P.Y. Ayala, K. Morokuma, G.A. Voth, P. Salvador, J.J. Dannenberg, V.G. Zakrzewski, S. Dapprich, A.D. Daniels, M.C. Strain, O. Farkas, D.K. Malick, A.D. Rabuck, K. Raghavachari, J.B. Foresman, J.V. Ortiz, Q. Cui, A.G. Baboul, S. Clifford, J. Cioslowski, B.B. Stefanov, G. Liu, A. Liashenko, P. Piskorz, I. Komaromi, R.L. Martin, D.J. Fox, T. Keith, M.A. Al-Laham, C.Y. Peng, A. Nanayakkara, M. Challacombe, P.M.W. Gill, B. Johnson, W. Chen, M.W. Wong, C. Gonzalez, J.A. Pople, Gaussian 03, revision D.01, Gaussian, Inc., Wallingford, CT, 2004.

[18] E.D. Glendening, J.K. Badenhoop, A.E. Reed, J.E. Carpenter, J.A. Bohmann, C.M. Morales, F. Weinhold, NBO 5.G, Theoretical Chemistry Institute. University of Wisconsin, Madison, WI, 2001

[19] M.W. Schmidt, K.K. Baldridge, J.A. Boatz, S.T. Elbert, M.S. Gordon, J.H. Jensen, S. Koseki, N. Matsunaga, K.A. Nguyen, S. Su, T.L. Windus, M. Dupuis, J.A. Montgomery, J. Comput. Chem. 14 (1993) 1347.

[20] B.W. Kenneth, Angew. Chem., Int. Ed. Engl. 25 (1986) 312.

[21] R.A. Klein, Chem. Phys. Lett. 425 (2006) 128.

[22] T. Steiner, Angew. Chem., Int. Ed. Engl. 41 (2002) 48

[23] M.M. Deshmukh, S.R. Gadre, L.J. Bartolotti, J. Phys. Chem. A 110 (2006) 12519

[24] I. Vorobyov, M.C. Yappert, D.B. DuPre, J. Phys. Chem. A 106 (2002) 668.

[25] Y.P. Chang, T.M. Su, T.W. Li, I. Chao, J. Phys. Chem. A 101 (1997) 6107.

[26] Yaqian Liu, Corey A. Rice, M.A. Suhm, Can. J. Chem. 82 (2004) 1006.

[27] C.F.P. Silva, M.L.T.S. Duarte, R. Fausto, J. Mol. Struct. (THEOCHEM) 482-483 (1999) 591.

[28] K. Ohno, Y. Inoue, H. Yoshida, H. Matsuura, J. Phys. Chem. A 103 (1999) 4283.

[29] A.E. Reed, L.A. Curtiss, F. Weinhold, Chem. Rev. 88 (1988) 899.

[30] J.P. Foster, F. Weinhold, J. Am. Chem. Soc. 102 (1980) 7211.

[31] F. Weinhold, C.R. Landis, Valency and Bonding: A Natural Bond Orbital DonorAcceptor Perspective, Cambridge University Press, New York, 2005.

[32] F. Weinhold, C.R. Landis, Chem. Educ. Res. Pract. 2 (2001) 91.

[33] F. Weinhold, NBO 5.0 Program Manual Theoretical Chemistry Institute, University of Wisconsin, Madison, 2001. 